Poster presentation

Open Access

\title{
Quality of life geriatric patients
}

Karamitsos Konstantinos*, Karakousis Konstantinos, Karadonta ArgiroulaVasiliki, Pagitsas Ioannis and Karadonta Ioanna

Address: A' Internal Clinic General Hospital Larissa Greece

* Corresponding author

from International Society on Brain and Behaviour: 3rd International Congress on Brain and Behaviour

Thessaloniki, Greece. 28 November - 2 December 2007

Published: 17 April 2008

Annals of General Psychiatry 2008, 7(Suppl I):SI7I doi:I0.II86/I744-859X-7-SI-SI7I

This abstract is available from: http://www.annals-general-psychiatry.com/content/7/SI/SI7I

(c) 2008 Konstantinos et al.; licensee BioMed Central Ltd.

\section{Background}

The geriatric population constitutes $18 \%$ of the population of our country.

Aim of our study was to study the quality of life of elderly individuals.

\section{Materials and methods}

Constituted 234 patients from which $60 \%$ were women and $40 \%$ men of average age of 75 years.

\section{Results}

$8 \%$ suffered from psychiatric diseases, 35\% from diseases of the cardiovascular system, $18 \%$ from diseases of the respiratory system, $22 \%$ from malignant diseases, $7 \%$ from inflammatory diseases, 7\%endocrine diseases and 3\% from various other diseases.

\section{Conclusions}

Old age is the time of the downfall of the individual which begins with the decrease of the bodily functions, in the $92 \%$ of patients there hardly exists an explicit medical problem and, in the $8 \%$ it concerns psychiatric disturbances, and there should be particular sensitisation towards geriatrics patients. 